\title{
Selection of outfitting and decorative materials for ship living accommodations from the point of view of toxic hazard in the initial phase of fire progress
}

\author{
Renata Dobrzyńska, Ph. D. \\ West Pomeranian University of Technology, Szczecin
}

\begin{abstract}
Upholstery furniture and bedding components which presently are required to satisfy conditions of resistance to only small fire setting sources, really constitute a serious source of toxic hazard. The proposed method of toxic hazard assessment in the initial phase of fire progress, due to thermal decomposition and combustion of materials, makes appropriate selection of outfitting materials for shipboard living and service accommodations already in ship design phase, possible. Practical application of the proposed algorithm of selection procedure of suitable outfitting and decorative materials intended for shipboard living accommodations would decrease fire toxic hazard level in such accommodations.
\end{abstract}

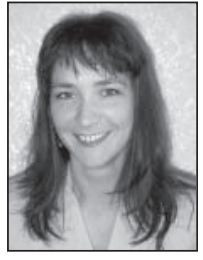

Keywords: fire safety of ship; quantitative method of toxic hazard assessment

\section{INTRODUCTION}

As results from subject-matter literature fire toxic hazard in shipboard living and service accommodations is high. Statistical data indicate that $36 \%$ fires on ships take place just in living and service accommodations.

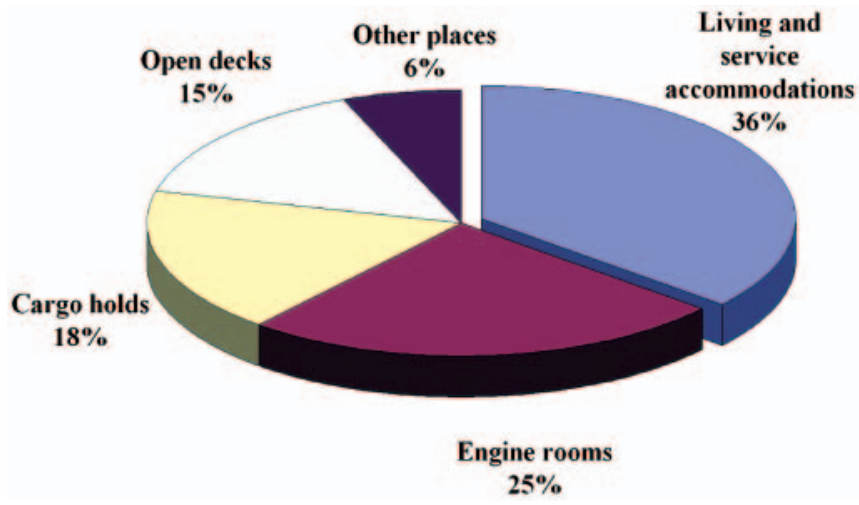

Fig. 1. Location of fire sources on ships [1]

The mentioned hazard due to toxic thermal decomposition of materials installed in shipboard living accommodations is also confirmed by consequences of real fires. The fire on the ferry ship „Scandinavian Star” has been numbered among the most tragic accidents of the kind. Out of 485 persons present on board 158 died as a result of fire. On the basis of casualty investigations it was stated that in about $94 \%$ cases decease was caused by action of carbon oxide and hydrogen cyanide emitted during thermal decomposition and combustion of materials used for the outfitting of cabins and corridor [2].

Outfitting materials (products) introduce serious thermal, smokiness and toxic risk. Yet upholstery furniture, decorative materials, bedding components are not covered by any test from the point of view of fire toxic hazard introduced by them - see IMO MSC. 61(67) resolution [3]. They are only to satisfy requirements for fire resistance against action of small fire setting sources. An upholstery system satisfies the Code requirements if it will pass the test of smouldering cigarette and flame equivalent of burning match. The exposure time to action of the flame is equal to 20s (Fig. 2). Enough to extend the time up to 30 s to start the upholstery system intensive burning (Fig. 3).

It means that the considered upholstery system which satisfies the rule requirements, is resistant to action of small fire setting sources only for $20 \mathrm{~s}$. In spite of the so moderate criterion many upholstery systems do not satisfy it. Therefore some fire-proofing agents which cause larger emission of smoke and toxic substances during fire, are added [5].

During fire people are exposed to action of a mixture of toxic substances. On assumption of additive influence of such mixture of toxic substances on human organism their concentration values $c_{i}$ in atmosphere of fire zone are to fulfil the condition:

$$
\sum_{i}^{\mathrm{n}} \frac{\mathrm{c}_{\mathrm{i}}}{\mathrm{LC}_{50 \mathrm{i}}^{30}}<1
$$

where:

$\mathrm{LC}_{50 \mathrm{i}}^{30}$ - limit concentration of $\mathrm{i}$-th substance, $\mathrm{g} \cdot \mathrm{m}^{-3}$ 


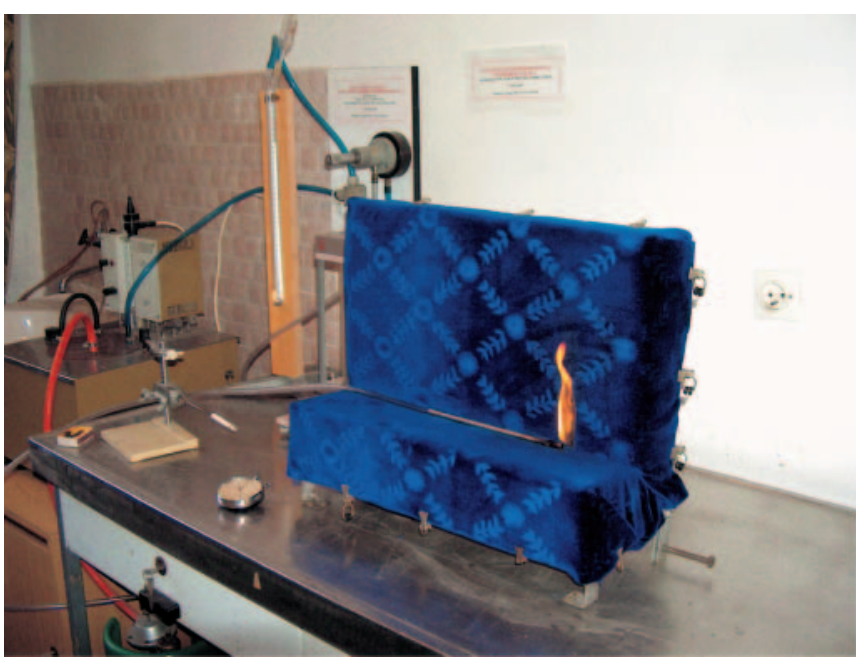

Fig. 2. Imflammability tests of upholstery furniture according to IMO FTP Code, Part 8 (test of torch flame equivalent to that of burning match) [4]; exposure time to flame action equal to $20 \mathrm{~s}$

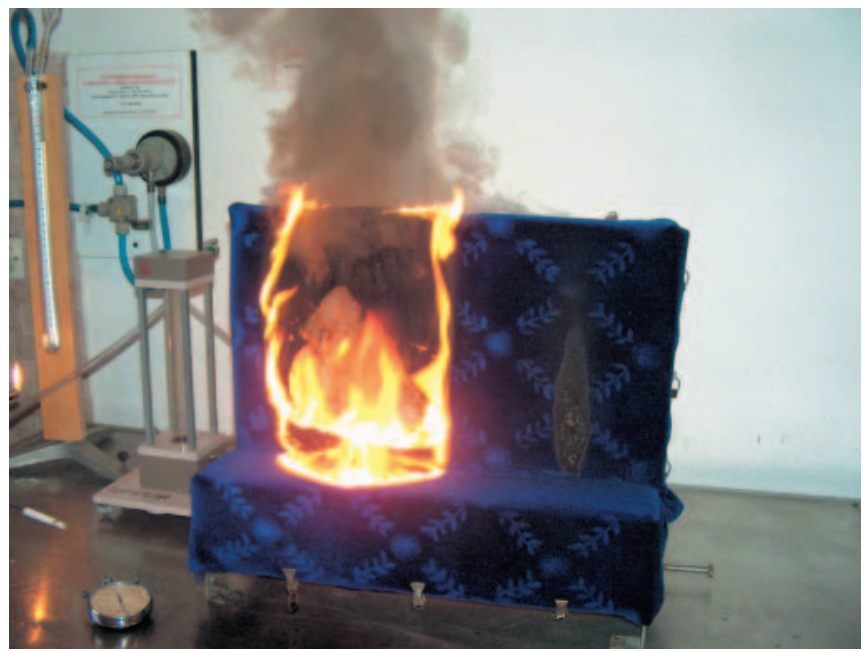

Fig. 3. Imflammability tests of upholstery furniture according to IMO FTP Code, Part 8 (test of torch flame equivalent to that of burning match) [4]; exposure time to flame action equal to 30 s.

During the time dt concentration of toxic substance in an accommodation changes by dc. In compliance with the principle of mass conservation the following equation can be written [6]:

$$
\mathrm{V}_{\text {pom }} \cdot \mathrm{dc}_{\mathrm{ij}}=\dot{\mathrm{m}}_{\mathrm{j}} \cdot \mathrm{E}_{\mathrm{ij}} \cdot \mathrm{dt}+\dot{\mathrm{V}} \cdot \mathrm{c}_{\mathrm{pij}} \cdot \mathrm{dt}-\dot{\mathrm{V}} \cdot \mathrm{c}_{\mathrm{ij}} \cdot \mathrm{dt}
$$

where:

$\mathrm{V}$ - accommodation volume, $\left[\mathrm{m}^{3}\right]$

$\dot{\mathrm{m}}_{\mathrm{j}}{ }^{\text {nom }}$ - mass combustion rate of $\mathrm{j}$-th material, [g. $\mathrm{s}^{-1}$ ]

$\mathrm{E}_{\mathrm{ij}}$ - mass emission rate of $\mathrm{i}$-th substance emitted during thermal decomposition and combustion of $\mathrm{j}$-th material, $\left[\mathrm{g} \cdot \mathrm{g}^{-1}\right]$

$\dot{V} \quad-$ air exchange rate, $\left[\mathrm{m}^{3} \cdot \mathrm{s}^{-1}\right]$

$\mathrm{c}_{\mathrm{ij}}$ - instantaneous concentration of $\mathrm{i}$-th toxic substance emitted during thermal decomposition and combustion of $\mathrm{j}$-th material, in air of accommodation, $\left[\mathrm{g} \cdot \mathrm{m}^{-3}\right.$ ]

$\mathrm{c}_{\mathrm{pij}}-$ concentration of $\mathrm{i}$-th toxic substance in intake air, $\left[\mathrm{g} \cdot \mathrm{m}^{-3}\right]$.

Hence it can be stated that mass change of $\mathrm{i}$-th component emitted from $\mathrm{j}$-th material exposed to fire is equal to sum of mass of $i$-th component emitted during combustion of $j$-th material within the time dt and mass of i-th component brought with ventilating air within the same time $\mathrm{dt}$.

Solution of the equation for all the components regarding their limit concentrations obtains the form as follows:

$$
\begin{aligned}
\sum_{j}^{\mathrm{k}} \sum_{\mathrm{i}}^{\mathrm{n}} \frac{\mathrm{c}_{\mathrm{ij}}}{\mathrm{LC}_{50 \mathrm{i}}^{30}} & =\sum_{\mathrm{j}}^{\mathrm{k}} \frac{\dot{\mathrm{m}}_{\mathrm{j}}}{\dot{\mathrm{V}}} \cdot \sum_{\mathrm{i}}^{\mathrm{n}} \frac{\mathrm{E}_{\mathrm{ij}}}{\mathrm{LC}_{50 \mathrm{i}}^{30}} \cdot\left(1-\mathrm{e}^{-\frac{\dot{\mathrm{V}}}{\mathrm{V}_{\text {pom }}} \cdot \mathrm{t}}\right)= \\
& =\sum_{\mathrm{j}}^{\mathrm{k}} \frac{\dot{\mathrm{m}} \mathrm{j}}{\dot{\mathrm{V}}} \cdot \mathrm{X}_{\mathrm{j}} \cdot\left(1-\mathrm{e}^{-\frac{\dot{\mathrm{V}}}{\mathrm{V}_{\mathrm{pom}}} \cdot \mathrm{t}}\right)
\end{aligned}
$$

under the assumption that distribution of their concentrations is uniform throughout entire accommodation. Such assumption can be made because in the initial phase of fire progress ship air-conditioning system which ensures the uniform distribution of concentrations, is under operation.

$$
X_{j}=\sum_{i}^{n} \frac{E_{i j}}{L C_{50 i}^{30}}
$$

where:

$\mathrm{Xj}$ - toxicological coefficient for products of thermal decomposition and combustion of $\mathrm{j}$-th material, $\left[\mathrm{m}^{3} \cdot \mathrm{g}^{-1}\right]$

In accordance with the assumed principle of safety against toxicity (1) the right side of Eq. 3 should not be greater than one:

$$
\sum_{\mathrm{j}}^{\mathrm{k}} \frac{\dot{\mathrm{m}}_{\mathrm{j}}}{\dot{\mathrm{V}}} \cdot \mathrm{X}_{\mathrm{j}} \cdot\left(1-\mathrm{e}^{-\frac{\dot{\mathrm{V}}}{\mathrm{V}_{\text {pom }}} \mathrm{t}}\right)<1
$$

For constant air exchange rate in the stationary time $\mathrm{t}=\infty$ the inequality takes the form:

$$
\sum_{\mathrm{j}}^{\mathrm{k}} \dot{\mathrm{m}}_{\mathrm{j}} \cdot \mathrm{X}_{\mathrm{j}}<\dot{\mathrm{V}} ; \mathrm{m}^{3} \cdot \mathrm{s}^{-1}
$$

Therefore it can be assumed that the fire safety condition for the initial phase of fire progress should be as follows: the ventilating air demand during fire, $\dot{V}_{\text {zap }}$, should be - with a view of toxic hazard - lower than the air exchange usually applied:

$$
\dot{\mathrm{V}}_{\text {zap }}=\sum_{\mathrm{j}}^{\mathrm{k}} \dot{\mathrm{m}}_{\mathrm{j}} \cdot \mathrm{X}_{\mathrm{j}} ; \mathrm{m}^{3} \cdot \mathrm{s}^{-1}
$$

On the basis of results of the author's tests of upholstery systems, toxicological indices as well as mass combustion rate of materials per unit area of their surface, were determined.

The obtained results have been used for quantitative assessment of selected living accommodations on board a cargo ship of B587 - IV/8 series, namely: captain's office and sleeping room, crew cabin, mess room, day room and recreation room, with taking into account gas exchange conditions existing in them. As composition of upholstery systems influences toxic hazard during fire [7] this author has performed a simulation of risk level for various combinations of upholstery systems which satisfied the maritime requirements in force.

Results of the performed simulation made it possible to elaborate an algorithm for selection of materials in the design stage (Fig. 4), whose application would lead to lower hazard of exposure to toxic products of thermal decomposition and combustion of the materials in living accommodations on ships. 


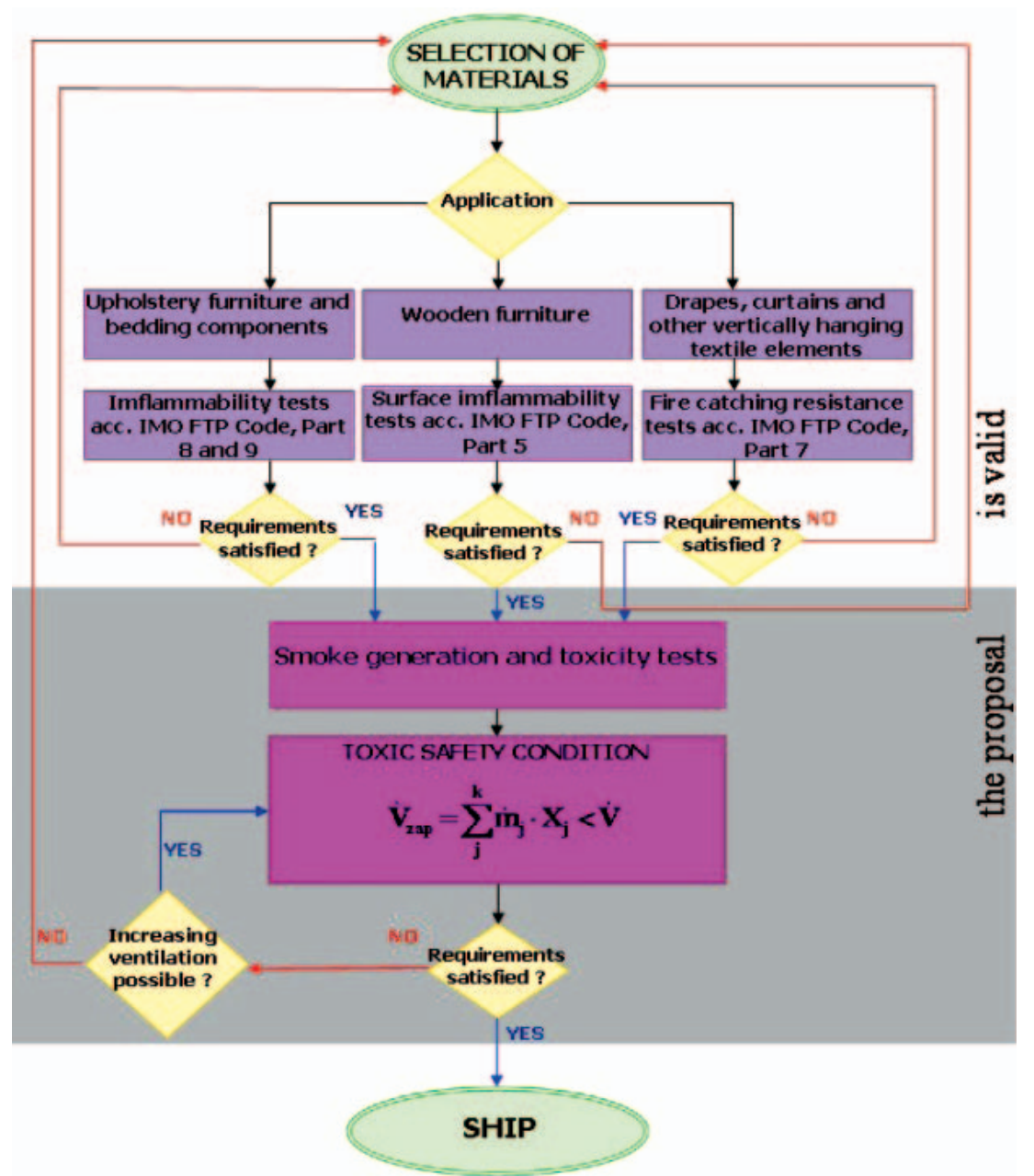

Fig. 4. Algorithm of selection procedure of suitable outfitting and decorative materials intended for applying to living accommodations on ships

\section{CONCLUSIONS}

Upholstery furniture and bedding components which are presently required to satisfy conditions of resistance to only small fire setting sources, really constitute a serious source of toxic hazard.

To quantitatively assess fire toxicity hazard in ship accommodations, knowledge of the following parameters is necessary:

- mass emission of toxic products of thermal decomposition and combustion of materials,

- mass combustion rate of materials.

On the basis of mass emission the toxicological indices for products of thermal decomposition and combustion, $\mathrm{Xj}$, can be determined.

In the initial phase of fire progress fulfillment of the following condition:

$$
\dot{\mathrm{V}}_{\text {zap }}=\sum_{\mathrm{j}}^{\mathrm{k}} \dot{\mathrm{m}}_{\mathrm{j}} \cdot \mathrm{X}_{\mathrm{j}}<\dot{\mathrm{V}}
$$

is necessary in order to ensure fire toxic safety.

The proposed assessment method of toxic hazard resulting from thermal decomposition and combustion of materials, makes appropriate selection of outfitting materials for ship living and service accommodations in ship design phase, possible.

Practical application of the elaborated method and proposed algorithm of selection procedure of suitable outfitting and decorative materials intended for ship living accommodations, would decrease fire toxic hazard level in living and service accommodations on ships.

\section{BIBLIOGRAPHY}

1. Grzywaczewski Z., Załęcki S.: Fire fighting on ships (in Polish). Maritime Publishing House (Wydawnictwo Morskie), Gdynia 1982

2. Robinson A., Burgoyne J.H.: The Scandinavian Star Incident. A Case Study. IFE Journal, 1999

3. IMO: International Code of Fire Testing Procedures (in Polish), IMO Resolution MSC. 61(67), London 1998

4. IMO: Fire resistance tests of upholstery furniture according to FTP Code (in Polish), Part 8, IMO Res. A.652(16), London 1998

5. Dobrzyńska R.: Influence of applied amount of fire-proofing agents on emission of toxic products of thermal decomposition of polyurethane foams (in Polish). 42nd Scientific Congress of Polish Chemical Society and Polish Society of Chemical Engineers and Technicians, Rzeszów 1999

6. Dobrzyńska R.: Toxic hazard level evaluation of ship rooms during initial phase of fire progress. Marine Technology Transactions, vol. 16, 2005

7. Dobrzyńska R.: Toxic hazard level assessment of ship accommodations during initial phase of fire progress (in Polish). $8^{\text {th }}$ Conference on Shipbuilding and Ocean Engineering - Development prospects of transport systems, Publ. of Szczecin Technical University, Szczecin 2006.

\section{CONTACT WITH THE AUTHOR}

Renata Dobrzyńska, Ph. D.

West Pomeranian University of Technology, Szczecin Faculty of Marine Technology

AL. Piastów 41

71-065 Szczecin, POLAND e-mail: Renata.Dobrzynska@zut.edu.pl 